\title{
Effect of Pregabalin Use as Preemptive Analgesia after Abdominal Hysterectomy on Heart Rate and Arterial Pressure
}

\author{
Kazi Nur Asfia', Moinul Hossain², AKM Aktaruzzaman³, Mostofa Kamal', \\ Md. Abdullah Yusuf ${ }^{5}$, Farhanaz Zainab ${ }^{6}$ \\ ${ }^{1}$ Assistant Professor, Department of Anaesthesiology, National Institute of Neurosciences \& Hospital, Dhaka, Bangladesh; \\ ${ }^{2}$ Professor (Pain Management), Department of Anaesthesia, Analgesia \& Intensice Care Medicine, Banghabandhu \\ Sheikh Mujib Medical University, Dhaka, Bangladesh; ${ }^{3}$ Professor (Neuroanaesthesiology), Department of \\ Anaesthesia, Analgesia \& Intensive Care Medicine, Banghabandhu Sheikh Mujib Medical University, Dhaka, \\ Bangladesh; ${ }^{4}$ Associate Professor, Department of Anaesthesia, Analgesia \& Intensive Care Medicine, \\ Banghabandhu Sheikh Mujib Medical University, Dhaka, Bangladesh; ${ }^{5}$ Assistant Professor, \\ Department of Microbiology, National Institute of Neurosciences \& Hospital, Dhaka, \\ Bangladesh; ${ }^{6}$ Junior Consultant (Anaesthesia), Department of Anaesthesiology, National \\ Institute of Neurosciences \& Hospital, Dhaka, Bangladesh
}

[Received: 21 January 2016; Revised: 6 March 2016; Accepted: 11 June 2016; Published: 1 July 2016]

\begin{abstract}
Background: Effect of pregabalin on heart rate and arterial pressure is important in its use as preemptive analgesia. Objective: The purpose of the present study was to evaluate the effect of pregabalin use as preemptive analgesia after abdominal hysterectomy on heart rate and arterial pressure. Methodology: This randomized double-blind placebo-controlled clinical trial was conducted in the Department of Anesthesia, Analgesia and Intensive Care Medicine, Banghabandhu Sheikh Mujib Medical University, Dhaka from July 2010 to June 2012 for a period of two years. Women aged between 40-60 years scheduled for abdominal hysterectomy under sub-arachnoid block were selected as study population for this study. A total of one hundred and twenty women meeting the above mentioned criteria were randomly allocated into two equal groups by card sampling. 120 cards, 60 for each group were prepared by another person who was not aware of the study. Group A was known as study group who were received $300 \mathrm{mg}$ oral pregnabin one hour before performance of $\mathrm{SAB}$ and group $\mathrm{B}$ was known as control group who were received matching placebo one hour before $\mathrm{SAB}$. The patients were examined preoperatively and preoperative baseline parameters including heart rate, mean arterial pressure were recorded immediately before sub-arachnoid block (SAB). Patients were visited by the investigators at $1 / 2,1,2,4,12$, and $24 \mathrm{~h}$ after operation. In each visit, heart rate and mean arterial pressure were measured and were recorded. Result: The present study was conducted on 120 women undergoing abdominal hysterectomy. Of them, 60 received preemptive single oral doses (300mg) Pregabalin (Group A) and the rest 60 received matching placebos (Group B) $1 \mathrm{hr}$ before surgery. The mean heart rate with SD before SAB was $79.4 \pm 4.7$ and $90.5 \pm 5.7$ in group A and B respectively ( $\mathrm{p}=0.011$ ). After 24 hours of operation the mean heart rate with SD was $73 \pm 5$ and $85 \pm 4$ in group A and B respectively $(\mathrm{p}=0.043)$. The mean arterial pressure with SD before SAB was $94.3 \pm 5.3$ and $95.8 \pm 20.4$ in group A and B respectively $(\mathrm{p}=0.569)$. After 24 hours of operation the mean arterial pressure with SD was $89.4 \pm 4.45$ and $96.1 \pm 2.56$ in group A and B respectively $(\mathrm{p}<0.001)$. Conclusion: In conclusion the mean heart rate and arterial pressure are statistically significantly changes in the women after abdominal hysterectomy to whom pregabalin is used as preemptive analgesia. [Journal of National Institute of Neurosciences Bangladesh, 2016;2(2): 98-102]
\end{abstract}

Keywords: Pregabalin; abdominal hysterectomy; preemptive analgesia

Correspondence: Dr. Kazi Nur Asfia, Assistant Professor, Department of Anaesthesiology, National Instritute of Neurosciences \& Hospital, Sher-E-Bangla Nagar, Dhaka-1207, Bangladesh; Email: shipu.asfia@gmail.com; Cell No.: +8801553423767

Conflict of interest: There is no conflict of interest relevant to this paper to disclose.

Funding agency: This research project was not funded by any group or any institution.

Contribution to authors: KNA, MH \& AKMA were contributed from the protocol preparation upto report writing. MK, MAY and FZ were involved in the manuscript writing and revision.

How to cite this article: Asfia KN, Hossain M, Aktaruzzaman AKM, Kamal M, Yusuf MA, Farhanaz Zainab F.Effect of Pregabalin Use as Preemptive Analgesia after Abdominal Hysterectomy on Heart Rate and Arterial Pressure. J Natl Inst Neurosci Bangladesh, 2016;2(2): 98-102

Copyright: (C2016 Asfia et al. Published by Journal of National Institute of Neurosciences Bangladesh. This article is published under the Creative Commons CC BY-NC License (https://creativecommons.org/licenses/by-nc/4.0/). This license permits use, distribution and reproduction in any medium, provided the original work is properly cited, and is not used for commercial purposes. 


\section{Introduction}

Postoperative pain is one of the common problems of the postoperative ward care. The pain relief is associated with alleviation of endocrine-metabolic response to surgery, inhibition of surgery related autonomic reflexes. These problems lead to muscle spasm and many other undesirable side effects ${ }^{1}$. In addition to the subjective comfort, postoperative pain management is provided to reduce pain induced autonomic and somatic responses. It allows the patients to breath, cough and to move more easily ${ }^{2}$. These are essential for the prevention of pulmonary and thromboembolic consequences ${ }^{3}$.

Pregabalin is a structural analogue of gama-amino-buteric acid (GABA), binds potently with alpha-2-delta subunit of presynaptic voltage- dependent calcium channels (N-type). These types of channels are present throughout the nervous system ${ }^{4-6}$. The European commission and food and drug administration first approved pregabalin in 2004 for the treatment of neuropathic pain and in 2005 for an adjunctive therapy in epilepsy. In 2006, the European Commission approved pregabalin for the treatment of generalized anxiety disorder ${ }^{7-8}$. The available literatures also suggested its efficacy in the management of acute pain $^{9-11}$. By acting as a $\mathrm{Ca}+$ channel blocker, it blocks release of certain excitatory neurotransmitter, like-glutamate, substance-P and CGRP ${ }^{12}$. In this way pregabalin causes inhibitory modulation of neuronal hyper excitability and can be used as an adjuvant to a multimodal analgesic regimen to achieve opioid sparing effects $^{11}$. The present study was designed to evaluate the effect of pregabalin use as preemptive analgesia after abdominal hysterectomy on heart rate and arterial pressure.

\section{Methodology}

Study Population and Study Design: This randomized double-blind placebo-controlled clinical trial was conducted in the Department of Anesthesia, Analgesia and Intensive Care Medicine, Banghabandhu Sheikh Mujib Medical University, Dhaka from July 2010 to June 2012 for a period of two years. Women aged between 40-60 years scheduled for abdominal hysterectomy under sub-arachnoid block were selected as study population for this study. The study populations were divided into group A who were received pregabalin and group B who were received matching placebo. The eligibility criteria of the patients were the age group between 40 to 60 years scheduled for abdominal hysterectomy under sub-arachnoid block, and ASA physical status I - II. Patietns with chronic pain syndromes and epilepsy, patients getting treatment with pregabalin for chronic pain, impaired renal function, bleeding diathesis, local skin infection, pre-existing neurological or spine disease were excluded fromt his study. Ethical guidelines of Helsinki Declaration VI were followed throughout the study. Following the approval from Institutional Review Board (IRB) \& after explaining the procedure of works, informed consent was obtained from all the patients.

Blinding and randomization: A total of one hundred and twenty women meeting the above mentioned criteria were randomly allocated into two equal groups by card sampling. 120 cards, 60 for each group were prepared by another person who was not aware of the study. Every patient in the study was allowed to choose a card pre-operatively. According to card selection, patients were grouped into group A and group B.

Allocation: Group A was known as study group who were received $300 \mathrm{mg}$ oral pregnabin one hour before performance of $\mathrm{SAB}$ and group $\mathrm{B}$ was known as control group who were received matching placebo one hour before SAB.

Anesthesia procedure: The patients were examined preoperatively and preoperative baseline parameters including heart rate, mean arterial pressure were recorded immediately before sub-arachnoid block (SAB). In the operating room, all patients were preloaded with Ringers lactate solution $10 \mathrm{ml} / \mathrm{kg}$ before administration of spinal anesthesia. The spinal anesthesia were administered at lumbar interspaces between L3-L4 in a mid line approach with $0.5 \%$ hyperbaric bupivacaine (3-3.5 ml). After SAB, patients were immediately placed in supine position. After completion of operation, all patients were taken to the recovery ward where patients were continuously monitored and managed for first 24 hours.

Outcomes Measure and Follow up: The intensity of pain was assessed with visual analogue scale (VAS: $0-10 \mathrm{~cm})$ which was explained to patient during preoperative visit. The time interval of onset of pain in the postoperative period was recorded. The postoperative nausea and vomiting (PONV) was managed with antiemetic drugs. Time of first dose of inj. Morphine in the post-operative ward was recorded and total dose of analgesic administered in the first 24 hrs was then calculated. Patients were visited by the investigators at $1 / 2,1,2,4,12$, and $24 \mathrm{~h}$ after operation. In each visit, the following parameters were measured and recorded $\mathrm{SpO} 2$, heart rate, respiratory rate, mean 
arterial pressure, and VAS pain score, sedation score, and the side effects developed. Finally, total 24 hours consumption of Morphine and time interval of first dose of Morphine from SAB was recorded.

Statistical analysis: Data are presented as mean \pm SD. Unpaired Student's t-Test was used for comparison of the two groups regarding baseline characteristics, haemodynamic status, VAS score and the morphine consumption. The incidence of side effects was compared using Chi-square (c2) Test and occurrence of somnolence in both group were analysed using Fischer's Exact Test. A p value $>0.05$ was interpreted as an indication of statistical significance, where confidence interval was $95 \%$.

\section{Results}

The present study was conducted on 120 women undergoing abdominal hysterectomy. Of them, 60 received preemptive single oral doses $(300 \mathrm{mg})$ Pregabalin (Group A) and the rest 60 received matching placebos (Group B) $1 \mathrm{hr}$ before surgery. The data was recorded immediately before $\mathrm{SAB}$ and at 30 minutes, $1 \mathrm{hr} .2 \mathrm{hrs}, 4 \mathrm{hrs}, 12 \mathrm{hrs}$ and $24 \mathrm{hrs}$ intervals in postoperative period. The groups were similar for age, weight, and ASA physical status (Table 1).

Mean values of the heart rate in the group A varies from the group $\mathrm{B}$. The mean heart rate with $\mathrm{SD}$ before SAB was $79.4 \pm 4.7$ and $90.5 \pm 5.7$ in group $A$ and $B$ respectively $(p=0.011)$. The mean heart rate after 30 minutes with SD of group A and B were $67 \pm 2$ and $83 \pm 2$ respectively $(\mathrm{p}=0.032)$. After 24 hours of operation the mean heart rate with $\mathrm{SD}$ was $73 \pm 5$ and $85 \pm 4$ in group A and B respectively ( $\mathrm{p}=0.043)$ (Table 2).
Table 1: Distribution of Patient Baseline Characteristics

\begin{tabular}{lccc}
\hline Variables & $\begin{array}{c}\text { Group A } \\
(\mathrm{n}=60)\end{array}$ & $\begin{array}{c}\text { Group B } \\
(\mathrm{n}=60)\end{array}$ & P value \\
\hline Age(in yrs)\# (mean \pm SD) & $43.9 \pm 4.7$ & $44.7 \pm 6.1$ & 0.341 \\
Weight(in kg)\# (mean \pm SD) & $53.7 \pm 7.2$ & $54.2 \pm 5.5$ & 0.668 \\
\hline ASA Status* & & & \\
\hline ASA Grade-I & $42(70.0)$ & $36(60.0)$ & 0.251 \\
ASA Grade-II & $18(30.0)$ & $24(40.0)$ & \\
\hline
\end{tabular}

Figures in the parenthesis denote corresponding \%. \# Data was analyzed using Student's t-Test and was presented as mean \pm SD. Chi-square (c2) Test was employed to analyze the* data; p-value $<0.05$ is significant.

Mean values of mean arterial pressure (MAP) in the group A varies from that of the group. Mean values of the mean arterial pressure in the group A varies from the group B. The mean arterial pressure with SD before $\mathrm{SAB}$ was $94.3 \pm 5.3$ and $95.8 \pm 20.4$ in group $\mathrm{A}$ and $\mathrm{B}$ respectively $(\mathrm{p}=0.569)$. The mean arterial pressure after 30 minutes with SD of group A and B were $86.8 \pm 2.9$ and $96.1 \pm 5.1$ respectively $(\mathrm{p}<0.001)$. After 24 hours of operation the mean arterial pressure with SD was $89.4 \pm 4.45$ and $96.1 \pm 2.56$ in group A and B respectively $(\mathrm{p}<0.001)$ (Table 3$)$.

\section{Discussion}

During the last decade, there has been increasing interest in the use of preemptive analgesia for postoperative pain relief. Preemptive analgesia has been shown to be more effective in control of post operative pain by protecting the central nervous system from deleterious effect of noxious stimuli ${ }^{13}$.

Preemptive analgesic modalities have been used as single entities and in combination. Regional and opioid analgesia has been studied extensively. A study

Table 2: Changes in Heart Rate in Different Period

\begin{tabular}{lccccccc}
\hline Group & Before SAB & \multicolumn{5}{c}{ Post-operative parameters } \\
\cline { 3 - 8 } & & After 30 min & After 1hr & After 2hrs & After 4hrs & After 12hrs & After 24hrs \\
\hline Group A (n=60) & $79.4 \pm 4.7$ & $67 \pm 2$ & $69 \pm 3$ & $70 \pm 1.6$ & $71 \pm 4$ & $71 \pm 4$ & $73 \pm 5$ \\
Group B (n=60) & $90.5 \pm 5.7$ & $83 \pm 2$ & $90 \pm 4$ & $99 \pm 3$ & $88 \pm 3$ & $88 \pm 3$ & $85 \pm 4$ \\
\hline P-value & 0.011 & 0.032 & $<0.001$ & $<0.001$ & 0.04 & 0.024 & 0.043 \\
\hline
\end{tabular}

Data was analyzed using Student's t-Test and was presented as mean \pm SD

Table 3: Changes in Mean Arterial Pressure (MAP) in Different Period

\begin{tabular}{lccccccc}
\hline Group & Before SAB & \multicolumn{7}{c}{ Post-operative parameters } \\
\cline { 2 - 7 } & & After 30 min & After 1hr & After 2hrs & After 4hrs & After 12hrs & After 24hrs \\
\hline Group A (n=60) & $94.3 \pm 5.3$ & $86.8 \pm 2.9$ & $88.4 \pm 3.19$ & $89.2 \pm 3.91$ & $89.1 \pm 2.93$ & $88.9 \pm 5.8$ & $89.4 \pm 4.45$ \\
Group B (n=60) & $95.8 \pm 20.4$ & $96.1 \pm 5.1$ & $96.8 \pm 2.2$ & $104.2 \pm 8.07$ & $93.95 \pm 6.17$ & $92 \pm 15.6$ & $96.1 \pm 2.56$ \\
\hline P-value & 0.569 & $<0.001$ & $<0.001$ & $<0.001$ & 0.003 & $<0.001$ & $<0.001$ \\
\hline
\end{tabular}

Data was analyzed using Student's t-Test and was presented as mean \pm SD 
demonstrates the ability of preemptive analgesic interventions to attenuate postoperative pain scores, decrease supplemental postoperative analgesic requirements, and prolong time to first rescue analgesic request ${ }^{14}$. Using these outcome measures, preemptive analgesia showed an overall beneficial effect after epidural analgesia, local wound infiltration, and systemic nonsteroidal anti-inflammatory drug administration. Pre-incisional analgesia has been shown to be more effective in control of post-operative pain by protecting the central nervous system from deleterious effects of noxious stimuli and resulting allodynia and increased pain. Gabapentin and pregabalin have antiallodynic and antihyperalgesic properties useful for treating neuropathic pain and may also be beneficial in acute post-operative pain managemant ${ }^{15}$.

Pregabalin is a gabapentinoid drug useful for treating neuropathic pain. It has no effect on nociceptors but by blocking the CNS N-type calcium channel it may reduce the release of excitatory neurotransmitter and thereby it can reduce the hyper excitability of dorsal horn neurons which are induced by tissue damage. Therefore, it may also be beneficial in acute post-operative pain. Several studies have reported its usefulness as adjuvant analgesic to opioid in acute pain management where opioid related side effects are reduced with higher patient satisfaction ${ }^{16-18}$.

This study was designed to evaluate the effect of pregabalin after its preemptive administration in reducing postoperative pain. In Group A, the patients received $300 \mathrm{mg}$ pregabalin 1 hour before abdominal hysterectomy under sub-arachnoid block with $0.5 \%$ hyperbaric bupivacaine. More intensive analgesia (VAS scores less than $3 \mathrm{~cm}$ ) was observed in pregabalin group than placebo group. In a large number of studies similar analgesic effect was obtained, where the type of surgery and mode of anesthesia was different ${ }^{19-20}$. The duration of analgesia following SAB was longer in group A $(5.2 \pm 0.4)$ as compared to group B $(2.3 \pm 0.2)$. The difference was highly significant and somewhat different from previous studies ${ }^{21}$.

The limitation of this study design was that the single dose of pregabalin had been used. The half-life of pregabalin is 5-7 hrs and can not provide as a sole agent for covering postoperative pain management. Further studies are needed to determine the long term benefits, if any. The real challenge in the clinical setting is not simply to minimize the dose of morphine consumption but to minimize long-term side effects and occurrence of chronic pain syndromes within week or month after surgery.

\section{Conclusion}

It can be concluded that pregabalin can be an effective tool in the armamentarium of anaesthesiologist in the treatment of postoperative pain. Furthermore, the mean heart rate and arterial pressure are statistically significantly changed in the women after abdominal hysterectomy to whom pregabalin is used as preemptive analgesia.

\section{References}

1. Kehlet H, Dahl JB. The value of multimodal or balanced analgesia in postoperative pain treatment. Anesth Analg 1993; 77:1048-56

2. Atkinson RS, Rushman GB, Davies NJH .Acute pain. Lee's Synopsis of Anaesthesia. 11th edn. Butterworth-Heinemann 1993; 750

3. Arikkath J, Campbell KP. Auxiliary subunits: essential component of the voltage-gated calcium channel complex. Curr Opin Neurobiol 2003; 13:298-307

4. Gee NS, Brown JP, Dissanayake VUK, Offord J, Thurlow R, Woodruff GN. The novel anticonvulsant drug, gabapentin (Neurontin), binds to the _-2-_ subunit of a calcium channel. J Biol Chem 1996; 271:57 $\overline{6} 8-\overline{76}$

5. Taylor C. The biology and pharmacology of calcium channel 2proteins. CNS Drug Rev 2004;10:183-8

6. Forde G. Adjuvant analgesics for the treatment of neuropathic pain: evaluating efficacy and safety profiles. J Fam Pract 2007; $56: 3-12$

7. Gilron I, Watson C,NP,Cahill CM, Moulin DE. Neuropathic pain: a practical guide for the clinician. CMAJ 2006; 175:265-75

8. Reuben SS, Buvanendran A, Kroin JS, Raghunathan K. The analgesic efficacy of celecoxib, pregabalin, and their combination for spinal fusion surgery.Anaes-analgesia 2006; 103:1271-7

9. Agarwal, S. Gautam, D. Gupta, S. Agarwal, P. Singh, K. and Singh, U. Evaluation of a single preoperative dose of pregabalin for attenuation of postoperative pain after laparoscopic cholecystectomy, British J Anaesth 2008;101(5):700-4

10. Tiippana E M, Hamunen K, Kontinen V K and Kalso E. Do surgical patients benefit from perioperative gabapentin/pregabalin? A Systematic Review of Efficacy and Safety. Anesth Analg 2007; 104:1545-1556

11. Gajraj NM. Pregabalin: its pharmacology and use in pain management. Anesth Analg 2007; 105: 1805-15

12. Elia N, Lysakowski C, Tramer MR. Does multimodal analgesia with acetaminophen, non-steroidal anti-inflammatory drugs, or selective cyclooxygenase-2 inhibitors and patient-controlled analgesia morphine offer advavantages over morphine alone? Meta-analyses of randomized trials. Anaesthesiology 2005; 103:1296-304

13. Hill CM, Balkenohl M, Thomas DW, Walker R, Mathe H, Murray G. Pregabalin in patients with postoperative dental pain. Eur J Pain 2001; 5: 119-24

14. Mathiesen O, Mtiniche S and Dahl J B. Gabapentin and postoperative pain: a qualitative and quantitative sys $\neg$ tematic review, with focus on procedure. BMC Anesthesiology 2007; 7:6

15. Murphy NG, Mosher L. Severe myoclonus from pregabalin (Lyrica) due to chronic renal insufficiency. Clin Tox 2008; 46: 594 16. White PF. Multimodal analgesia: its role in preventing postoperative pain. Curr Opin Investing Drugs 2008; 9: 76-82

17. White PF, Kehlet H. Improving pain management: are we jumping from the frying pain into fire? Anesth-analg 2005; 105:10-12 
18. Jokela R, Ahonen J, Tallgren M, Haanpaa M and Korttila K. Premedication with pregabalin 75 or $150 \mathrm{mg}$ with ibuprofen to control pain after day-case gynaecological laparoscopic surgery. British Journal of Anaesthesia 2008;100 (6): 834-40

19. Crofford LJ, Rowbotham MC, Mease PJ, et al. Pregabalin for the treatment of fibromyalgia syndrome: results of a randomized, double-blind, placebo-controlled trial. Arthritis Rheum 2005;

\section{2:1264-1273}

20. Baselt R. Disposition of Toxic Drugs and Chemicals in Man (8th Edition ed.). Biomedical Publications, FosterCity, CA, 2008:1296-1297

21. Kehlet H, Wilmore DW. Multimodal strategies to improve surgical outcome. Am J Surg 2002; 183: 63041 